Z. klin. Chem. u. klin. Biochem.

Jg. 8., S. 329-338, Juli 1970

\title{
Neue Methoden zur Bestimmung von Steroidhormonen
}

\author{
Von H. Breuer ${ }^{1}$ ), Lieselotte Nocke und L. SiekmanN \\ Aus dem Institut für Klinische Biochemie und Klinische Chemie der Universität Bonn
}

(Eingegangen am 4. Juni 1970)

Während der letzten Jahre haben zwei neue empfindliche Methoden zur Bestimmung von Steroidhormonen in Körperflüssigkeiten zunehmend an Bedeutung gewonnen. Dabei handelt es sich einmal um die unter dem Begriff der Sättigungsanalyse zusammengefaßten kompetitiven Proteinbindungsmethoden, zum anderen um die Gaschromatographic und die Kombination dieser Technik mit der Massenspektrometrie.

Bei der Bestimmung von Steroidhormonen mit Hilfe der Proteinbindungsmethoden können entweder Plasmaproteine, Gewebeproteine oder Antikörper als Reagenzeiweiße verwendet werden. Auf folgende, methodisch wichtigen Punkte wird näher eingegangen: Spezifität, Affinität der Steroide zu den Proteinen, Abhängigkeit der Bindung von der Temperatur, der Ionenstärke und dem pH-Wert, Empfindlichkeit und Anwendungsbereich. Als Beispiel wird eine kompetitive Proteinbindungsmethode beschrieben, mit deren Hilfe es möglich ist, unter Verwendung von Plasma- und Gewebeproteinen in einer Plasmaprobe Testosteron, Progesteron, Östradiol-17 $\beta$ und Östron zu bestimmen. Ferner wird kurz auf eine radioimmunochemische Methode zur Bestimmung von Östradiol-17 $\beta$ hingewiesen. Bedingt durch ihre hohe Empfindlichkeit (picogramm-Bereich) sind die kompctitiven Proteinbindungsmethoden sehr störanfällig; die Einarbeitungszeit erfordert im allgemeinen mehrere Monate.

Bei der Gaschromatographie wird ein hochwirksames Trennverfahren mit einem sehr empfindlichen quantitativen Substanznachweis verbunden. Die Leistungsfähigkeit gaschromatographischer Säulen wird am Beispiel einer Trennung von Ring B-hydroxylierten phenolischen Steroiden demonstriert. Durch den Einsatz von Elektronen-Einfangdetektoren wird eine besonders große Empfindlichkeit erzielt. Zu diesem Zweck müssen die Steroide jedoch in halogenhaltige Derivate überführt werden.

In jüngster Zeit hat sich die Kombination Gaschromatographie-Massenspektrometrie in der Steroidanalytik bewährt. Es werden zwei Möglickeiten zum Einsatz dieser Gerätekombination beschrieben. Einmal können durch Aufnahme vollständiger Massenspektren im Säuleneluat nicht nur bekannte und unbekannte Steroide identifiziert werden, sondern auch gaschromatographische Bestimmungsverfahren auf ihre Spezifität geprüft werden. Zum andern kann das Massenspektrometer als hochspezifischer Detektor für den Gaschromatographen benutzt werden. Dies erfolgt durch Einstellung des Massenspektrometers auf geeignete substanzcharakteristische $\mathrm{m} / \mathrm{e}-\mathrm{Werte}$ mit Hilfe des Multiple Ion Detectors. Die kontinuierliche Aufzeichnung der eingestellten m/e-Werte ergibt Gaschromatogramme, bei denen spezifisch nur solche Substanzen angezeigt werden, deren Massenspektren die charakteristischen $\mathrm{m} / \mathrm{e}$-Werte aufweisen. Die hier beschriebene Methode stellt - im Gegensatz zu den bisher bekannten physikalisch-chemischen Verfahren - eine erhebliche Vereinfachung bei hoher Empfindlichkeit und Spezifität dar. Die Brauchbarkeit des Verfahrens wird am Beispiel einer Bestimmung von Östriol im Schwangerenplasma sowie von Aldosteron im Urin des Menschen beschrieben.

\section{New metbods for the determination of steroid bormones}

During recent years, two new sensitive methods for the determination of steroid hormones in body fluids have become of increasing importance. The first group of methods comprises the so called competitive protein binding methods which may be summarised under the term "saturation analysis". The second group consists of gas chromatography and the combination of this method with mass spectrometry.

When determining steroid hormones by means of protein binding methods, either plasma proteins, tissue proteins or antibodies can be used as reagent proteins. The following methodologically important points are discussed: specificity, affinity of steroids to proteins, dependence of the binding upon temperature, ionic strength and $\mathrm{pH}$-value, sensitivity and applicability. A competitive protein binding method is described by which testosterone, progesterone, oestradiol-17 $\beta$ and oestrone can be determined in one plasma sample, using plasma and tissue proteins as reagents. Furthermore, a radioimmunochemical method for the assay of oestradiol-17 $\beta$ is described briefly. Due to their high sensitivity (picogramm amounts), the competitive protein binding methods are difficult to perform properly. In general, it requires several months to set up a protein binding method.

Gas chromatography combines a highly efficient separation with a very sensitive quantitative detection. The efficiency of gas chromatography columns is demonstrated by the separation of ring B-hydroxylated phenolic steroids. By the use of electron capture detector, a very high sensitivity is achieved; however, only halogenated derivatives of steroids are suitable for gas chromatography with the electron capture detector.

More recently, the combination of gas chromatography with mass spectrometry has become of great value in the analysis of steroids. Two possibilities for the use of this combination will be discussed. Firstly, by scanning the mass spectra of the eluates, obtained after gas chromatography, it is not only possible to identify known or unknown steroids, but the specificity of the gas chromatographic methods may also be checked. Secondly, the mass spectrometer may be used as a highly specific detector for gas chromatography. This is done by setting the mass spectrometer to characteristic $\mathrm{m} / \mathrm{e}$-values, using a multiple ion detector. The continuous recording of the $\mathrm{m} / \mathrm{e}$-values yield's gas chromatograms, which specifically show only those substances, whose mass spectra have the characteristic $\mathrm{m} / \mathrm{e}$-values. In contrast to the hitherto known physical-chemical methods, the technique described here is much more simple and has, in addition, a high sensitivity and specificity. The applicability of this technique is demonstrated by the determination of oestriol in pregnancy plasma and of aldosterone in human urine.

1) Vorgetragen auf der Tagung Biochemische Analytik 70, München, 29. 4. - 2. 5. 1970. 
Das Gebiet der Steroidanalytik hat während der letzten fünf Jahre eine überaus schnelle Entwicklung erlebt, die sich eher beschleunigt als verlangsamt. Diese Tatsache dürfte im wesentlichen auf zwei Ursachen zurückzuführen sein. Einmal ergab sich bei der Durchführung von Steroidstoffwechselstudien die dringende Notwendigkeit, physiologische Konzentrationen von Steroidhormonen in geringen Mengen von biologischem Material zu bestimmen; das bedeutete, daß noch Nanogramm- bis Picogramm-Mengen von Steroiden qualitativ und quantitativ in einer Untersuchungsprobe nachzuweisen waren. Zum anderen erhielt die Steroidanalytik durch neue methodische Ansätze und Möglichkeiten starke Impulse, die ihrerseits zur Entwicklung hochempfindlicher und spezifischer Methoden führten. Im folgenden soll auf zwei Schwerpunkte der modernen Steroidanalytik eingegangen werden. Dabei handelt es sich einmal um die unter dem Begriff der Sättigungsanalyse zusammengefaßten Methoden, zum anderen um die Weiterentwicklung der Gaschromatographie und die Verwendung des Massenspektrometers.

\section{Sättigungs̀analyse}

Die Sättigungsanalyse ist ein analytisches Verfahren, bei dem die nachzuweisende Verbindung ein spezifisches Reagenz in zunehmendem $\mathrm{Maße}$ sättigt. Es handelt sich hierbei um eine besondere Art der Sättigung, die dann vorliegt, wenn die nachzuweisende Substanz das Reagenz gesättigt hat. Bei der Sättigungsanalyse von Steroidhormonen ist das Reagenz fast stets ein Protein; aus diesem Grunde wird für dieses Verfahren der Begriff "Proteinbindungsmethode" verwandt.

Die bei den einzelnen Proteinbindungsmethoden benutzten Proteine können verschiedener Herkunft sein; bevor dieser Punkt näher erläutert und durch Beispiele belegt wird, soll kurz auf das Prinzip der Sättigungsanalyse eingegangen werden (1). Dieses ist in Abbildung 1 dargestellt. Der im biologischen Material nachzuweisenden Verbindung $S$ wird eine definierte Menge von radioaktiv-markiertem $\mathrm{S}\left(\mathrm{S}^{*}\right)$ zugesetzt; exogenes und endogenes $S$ werden equilibriert. Falls erforderlich, wird

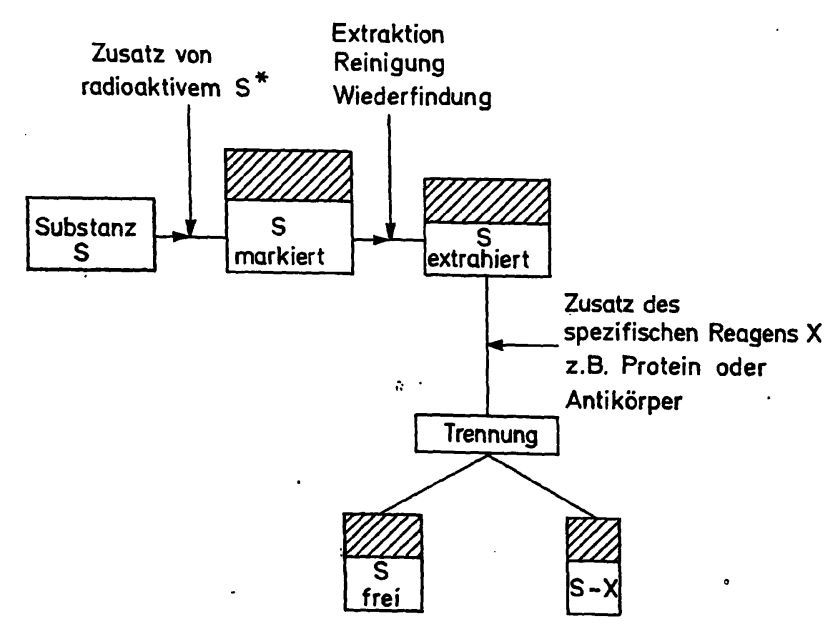

Abb. 1

Prinzip der Sättigungsanalyse nach EkINS und Newman (1) zur Abtrennung störender Verunreinigungen Substanz S extrahiert und der Extrakt gereinigt; zur Bestimmung der Wiederfindung wird die Radioaktivität in einem aliquoten Teil des Extraktes gemessen. Anschließend wird die nachzuweisende Substanz $S$ mit einem spezifischen Reagenz X (z. B. einem Protein oder Antikörper) gemischt. Dabei reagiert ein Teil der Substanz $S$ mit dem Reagenz X (gebundenes S), während ein weiterer Teil der Substanz $S$ nicht reagiert (freies $S$ ). Durch geeignete Verfahren (z. B. Dialyse, Adsorption, Gelfiltration, Elektrophorese) werden freies und gebundenes $S$ voneinander getrennt. Die quantitative Bestimmung erfolgt durch Messung der Radioaktivität entweder in der gebundenen oder in der freien Fraktion.

Für die Analytik von Steroidhormonen sind bisher mehrere brauchbare Methoden beschrieben worden, die als Radioliganden- bzw. kompetitive ProteinbindungsMethoden und als radioimmunochemische Methoden bezeichnet werden. Aus Gründen der Übersichtlichkeit werden alle diese Verfahren im folgenden als Proteinbindungs-Methoden zusammengefaßt besprochen. Je nach Art der Proteinbindungs-Methode werden als spezifische Reagenzien (1) Gewebsproteine, (2) Plasmaproteine oder (3) Antikörper verwendet.

Tab. 1

Zusammenstellung der wichtigsten Steroidhormone, die mit Hilfe kompetitiver Proteinbindungsmethoden unter Verwendung von Plasmaproteinen, Gewebeproteinen und Antikörpern bestimmt werden maproteinen, Gewebeproteinen und A

\begin{tabular}{|c|c|c|}
\hline Plasmaproteine & Gewebeproteine & Antikörper \\
\hline 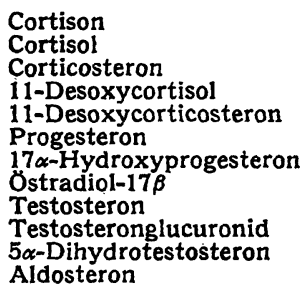 & $\begin{array}{l}\text { Östradiol-17 } \beta \\
\text { Östron } \\
\text { Östriol } \\
\text { Aldosteron }\end{array}$ & $\begin{array}{l}\text { Östradiol-17 } \beta \\
\text { Östron } \\
\text { Aldosteron } \\
\text { Progesteron }\end{array}$ \\
\hline
\end{tabular}

Die wichtigsten, mit Hilfe der genannten Proteine bestimmbaren Steroidhormone sind in Tabelle 1 zusammengestellt (2). Unter Verwendung von Plasmaproteinen kann neben Cortisol eine größere $\mathrm{Zahl}$ von $\mathrm{C}_{21^{-}}$ und $\mathrm{C}_{19}$-Steroiden nachgewiesen werden. Bei den Plasmaproteinen, die zur Bestimmung dieser Steroidhormone verwendet werden, handelt es sich einmal um das schon seit längerem bekannte Cortisol-bindende Globulin (CBG; Transcortin), zum anderen um das noch nicht genauer charakterisierte Sexualhormonbindende Globulin (SHBG). Gewebsproteine sind erst in jüngster Zeit mit Erfolg bei Proteinbindungsmethoden eingesetzt worden. So gelingt die quantitative Bestimmung kleinster Mengen von Östrogenen mit Gewebsproteinen aus Uterus (3) und von Aldosteron mit Gewebsproteinen aus Niere (4). Schließlich sei erwähnt, daß die radioimmunochemische Bestimmung von Östrogenen, Androgenen, Progesteron und Aldosteron mit Antikörpern möglich ist (5).

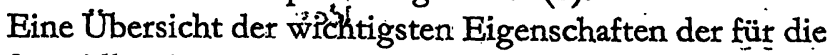
Steroidbestimmung geeigneten Proteine gibt Tabeille 2. 
Tab. 2

Zusammenfassung der wichtigsten. Elgenschaften der für die Bestimmung von Steroiden geeigneten Proteine. Nach MURPHY (2)

\begin{tabular}{|c|c|c|c|}
\hline Eigenschaften & Plasmaproteine & Gewebeproteine & Antikörper \\
\hline $\begin{array}{l}\text { Assoziationskon- } \\
\text { stante }\end{array}$ & $10^{7}-10^{10}$ (niedrig) & hoch & sehr hoch \\
\hline $\begin{array}{l}\text { Spezifität } \\
\text { a) Ausma:B } \\
\text { b) Relation zur }\end{array}$ & gering & mittel & potentiell hoch \\
\hline Aktivität & mäßig & groß & keine \\
\hline $\begin{array}{l}\text { Stabilität bei der } \\
\text { Aufbewahrung }\end{array}$ & stabil & instabil & stabil \\
\hline $\begin{array}{l}\text { Titer } \\
\text { Gewinnung }\end{array}$ & $\begin{array}{l}\text { niedrig } \\
\text { durch Verdünnung }\end{array}$ & $\begin{array}{l}\text { niedrig } \\
\text { durch Zellfrak- } \\
\text { tionierung }\end{array}$ & $\begin{array}{l}\text { sehr hoch } \\
\text { durch Immuni- } \\
\text { sierung }\end{array}$ \\
\hline (Zeitbedarf) & (Minuten) & (Stunden) & (Wochen) \\
\hline
\end{tabular}

Die Assoziationskonstanten der Plasmaproteine, der Gewebsproteine und der Antikörper zeigen erhebliche Unterschiede. Das gleiche gilt für die Spezifität der verschiedenen Proteine. Von großer praktischer Bedeutung ist die Stabilität sowie die Art der Gewinnung der verschiedenen Proteine. Plasmaproteine und Antikörper sind stabil, Gewebsproteine dagegen relativ instabil. Die Gewinnung von Plasmaproteinen erfordert Minuten, die von Gewebsproteinen Stunden und die von Antikörpern Wochen.

Von entscheidender Bedeutung für die Anwendbarkeit der Proteinbindungs-Methoden ist die Frage ihrer Spezifität. Dieses trifft insbesondere für diejenigen Methoden zu, bei denen die quantitative Bestimmung mit Plasma- oder Gewebsproteinen erfolgt. Die geringe Spezifität der Proteine, die bei den ProteinbindungsMethoden als Reagenzien verwendet werden, findet ihren Ausdruck in den relativen Bindungsaffinitäten gegenüber verschiedenen Steroiden. Dies soll für Plasmaproteine am Beispiel des Cortisol-bindenden Globulins und für Gewebeproteine am Beispiel des Östrogen-bindenden Globulins demonstriert werden. Wie aus Tabelle 3 hervorgeht, ist in verdünntem Plasma (1:10) die relative Bindungsaffinität des Cortisol-bindenden Globulins für Cortisol und Corticosteron gleich groß (6). Auch 21-Desoxycortisol und 11-Desoxycortisol werden in nennenswertem Maße gebunden. Die Bindungsaffinitäten des Cortisol bindenden Globulins $z u$ Progesteron und $17 \alpha-$ Hydroxyprogesteron betragen etwa die Hälfte derjenigen von Cortisol. Testosteron wird nur zu etwa 20\%, Óstradiol-17 $\beta$ dagegen praktisch nicht gebunden. Interessante Hinweise, die auch von großer analytischer Bedeutung sind, ergeben sich aus den relativen Bindungsaffinitäten des Östrogenbindenden Gewebsproteins aus Kaninchenuterus (7).

Tab. 3

Relative Bindungsaffinitäten des Cortisol-bindenden Globulins im Plasma (CBG; Transcortin). Nach MURPHY (6)

\begin{tabular}{lcc}
\hline Steroid & $\begin{array}{c}\text { Relative Bindungsaffinität } \\
\text { Unverdünntes } \\
\text { Plasma }\end{array}$ & $\begin{array}{c}\text { Plasma 1:10 } \\
\text { verdünnt }\end{array}$ \\
\hline Cortisol & 100 & 100 \\
Corticosteron & 86 & 100 \\
11-Desoxycortisol & 92 & 70 \\
21-Desoxycortisol & 90 & 90 \\
Progesteron & 15 & 55 \\
17 $\alpha$-Hydroxyprogesteron & 54 & 60 \\
11-Desoxycorticosteron & 40 & 50 \\
Cortison & 20 & 25 \\
Testosteron & - & 20 \\
Ostradiol-17 $\beta$ & - & $<1$ \\
\hline
\end{tabular}

Wie aus Tabelle 4 hervorgeht, wird Diäthylstilböstrol, ein synthetisches Östrogen, etwa zweieinhalb mal mehr gebunden als Östradiol-17 $\beta, 17 \alpha$-Äthinylöstradiol-17 $\beta$, das in vielen oralen Kontraceptiva enthalten ist, zeigt eine fast doppelt so hohe Bindungsaffinität zum Östrogen-bindenden Globulin wie Östradiol-17 $\beta$. Dagegen liegen die Werte für die relative Bindungsaffinität zum Östron und $z u$ der isomeren Verbindung Östradiol-17 $\alpha$ deutlich niedriger; das gilt in besonderem $\mathrm{Maße}$ auch für Östriol.

Die in den Tabellen 3 und 4 wiedergegebenen Werte bestätigen die oben getroffene Feststellung, daß die Plasma- und Gewebeproteine nicht spezifisch sind. Um die Spezifität der Proteinbindungs-Methoden zu erhöhen, ist deshalb - je nach Fragestellung - eine besondere Abtrennung und Reinigung des zu unter-

Tab. 4

Relative Bindungsaffinitäten des Ostrogen-bindenden Gewebsproteins aus Kaninchenuterus. Nach KORENMAN (7)

\begin{tabular}{|c|c|}
\hline Steroid & $\begin{array}{c}\text { Relative } \\
\text { Bindungsaffinität }\end{array}$ \\
\hline 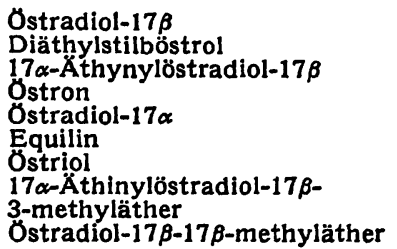 & $\begin{array}{r}100 \\
246 \\
191 \\
66 \\
49 \\
24 \\
16 \\
8 \\
3\end{array}$ \\
\hline
\end{tabular}

suchenden Steroids vor der eigentlichen Bestimmung notwendig. So kann z. B. Progesteron aus dem Plasma, in dem Cortisol bestimmt werden soll, durch Extraktion mit Petroläther entfernt werden. Bei der Bestimmung von Östron, Östradiol-17 $\beta$ und Östriol im Plasma von Frauen, die orale Kontraceptiva erhalten, ist eine Abtrennung der natürlichen Östrogene von den synthetischen z. B. durch Chromatographie an Celite oder Sephadex erforderlich.

Von besonderer Bedeutung für die Reproduzierbarkeit der Proteinbindungs-Methoden sind zahlreiche Fakto-

Tab. 5

Einfluß der Temperatur auf die Assoziationskonstanten $\mathrm{K}$ von SteroidCBG-Komplexen in verschiedenen Seren. Nach WESTPHAL (8)

\begin{tabular}{|c|c|c|c|c|c|c|}
\hline \multirow[t]{2}{*}{ Spezies } & \multicolumn{6}{|c|}{$\underset{\text { Cortisol }}{\text { Assoziationskonstante } \mathrm{K} \text { in } 10^{8} \mathrm{M}^{-1} \underset{\text { für }}{\text { Corticosteron }}} \begin{array}{c}\text { Pro- } \\
\text { gesteron }\end{array}$} \\
\hline & $4^{\circ}$ & $37^{\circ}$ & $4^{\circ}$ & $37^{\circ}$ & $4^{\circ}$ & $37^{\circ}$ \\
\hline $\begin{array}{l}\text { Mensch } \\
\text { Affe } \\
\text { Ratte } \\
\text { Kaninchen } \\
\text { Meerschwein- } \\
\text { chen }\end{array}$ & $\begin{array}{c}6 \\
3 \\
3 \\
30 \\
10 \\
0,5\end{array}$ & $\begin{array}{l}0,3 \\
0,3 \\
0,1 \\
0,4 \\
0,04\end{array}$ & $\begin{array}{l}10 \\
5 \\
8 \\
1,1\end{array}$ & $\begin{array}{l}0,3 \\
1,4 \\
0,3 \\
0,2 \\
0,14\end{array}$ & $\begin{array}{r}7 \\
3 \\
4 \\
48\end{array}$ & $\frac{0,9}{\overline{3}}$ \\
\hline
\end{tabular}

ren, von denen die folgenden erwähnt seien. So beeinAlußt die Ionenstärke des Mediums ebenso wie der $\mathrm{pH}$ Wert die Bindung an das Protein. Aus diesem Grunde muß auf die Konstanthaltung dieser beiden Parameter besonders geachtet werden. Weiterhin ist die Bindungsfähigkeit stark temperaturabhängig. Die Assoziationskonstante nimmt, wie Tabelle 5 zeigt, ab, wenn die Temperatur zunimmt (8). Einige Autoren arbeiten im 
Bereich von $4-6^{\circ}$, andere bei Raumtemperatur. In allen Fällen ist jedoch eine Konstanthaltung der Temperatur zur Gewinnung reproduzierbarer Werte unbedingt erforderlich.

Wie bereits ausgeführt, muß im Verlauf der Proteinbindungs-Methode die freie, nicht an Protein gebundene, radioaktiv markierte Substanz von der an das Protein gebundenen Substanz getrennt werden. Diese Trennung wird häufig durch Adsorption und Präzipitation durchgeführt, wobei als Adsorbentien Florisil, Charcoal, Fullererde oder Ionenaustauscher benutzt werden. Hierbei ist besonders auf die strenge Einhaltung der Kontaktzeit zu achten, da die Reaktion zwischen dem Adsorbens und dem Liganden praktisch irreversibel ist, während die Reaktion zwischen dem Protein und dem Liganden häufig reversibel ist. Demnach handelt es sich bei der Kontaktzeit um eine kritische Größe.

Um den breiten Anwendungsbereich zu demonstrieren, den die Proteinbindungs-Methoden für die Steroidanalytik eröffnen, wird im folgenden ein von BORTH und Mitarbeitern (9) ausgearbeitetes Verfahren zur

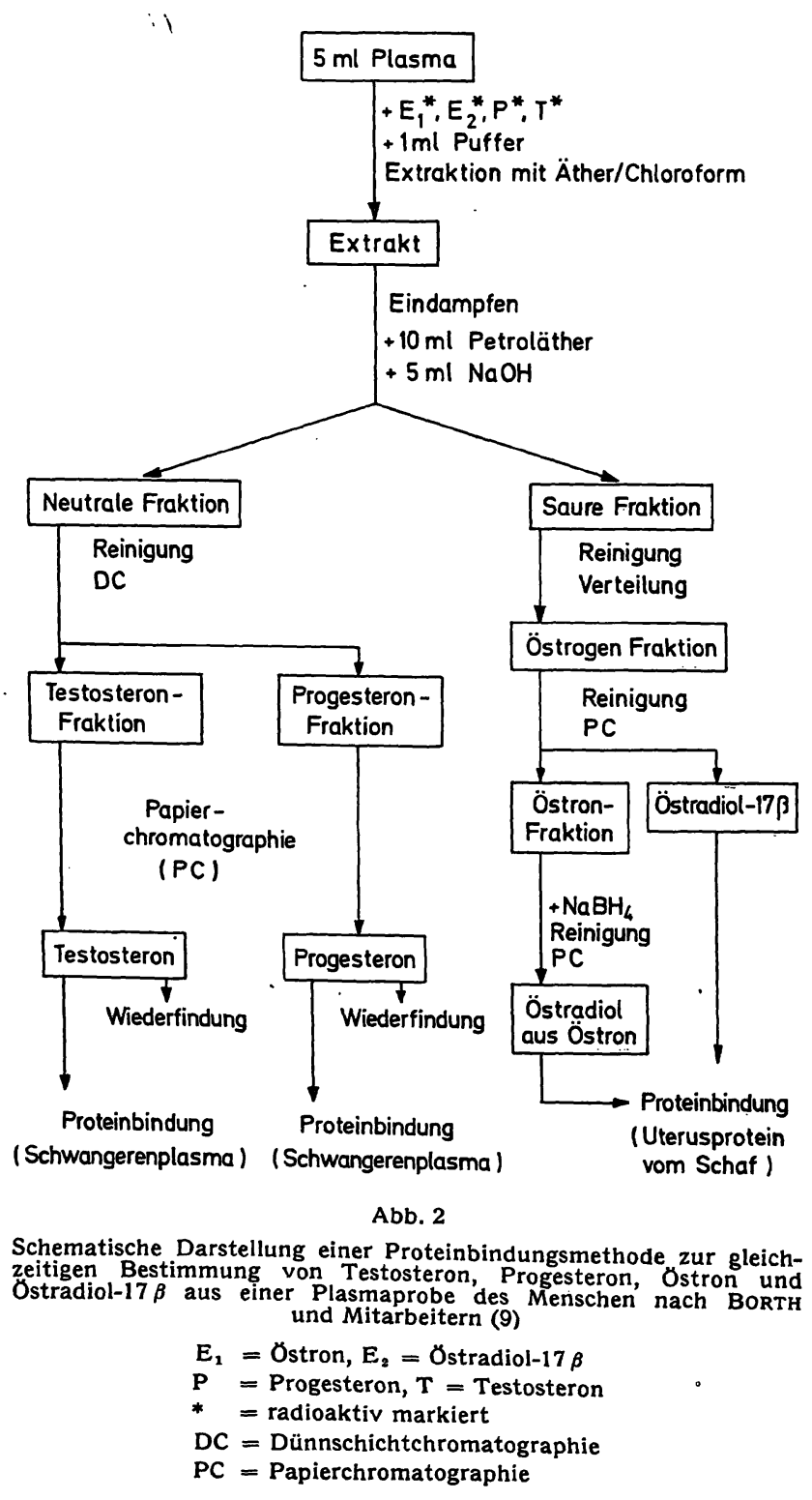

gleichzeitigen Bestimmung von Testosteron, Progesteron, Östron und Östradiol-17 $\beta$ beschrieben (Abb. 2). An diesem Beispiel wird die Notwendigkeit deutlich, wegen der nicht vorhandenen Spezifität der ReagenzProteine eine weitgehende Vortrennung der einzelnen Steroide durchzuführen. Im ersten Schritt der Methode werden $5 \mathrm{~m} l$ Plasma mit radioaktiv markiertem Östron, Östradiol-17 $\beta$, Progesteron und Testosteron versetzt und mit Äther/Chloroform extrahiert. Der Extraktrückstand wird zwischen Petroläther und Natronlauge verteilt. Die dabei gewonnenen neutralen und sauren Fraktionen werden getrennt aufgearbeitet. Die neutrale Fraktion wird dünnschichtchromatographisch in eine Testosteron- und in eine Progesteron-Fraktion aufgetrennt. Beide Fraktionen werden zur Beseitigung weiterer Verunteinigungen der Papierchromatographie unterworfen. Die so gewonnenen hochgereinigten Steroide werden durch Proteinbindung quantitativ bestimmt. Die saure Fraktion wird angesäuert und die Östrogen-Fraktion mit Benzol/Petroläther extrahiert. Die Östrogen-Fraktion wird papierchromatographisch in Östron und Östradiol-17 $\beta$ aufgetrennt. Während die Bestimmung von Östradiol-17 $\beta$ direkt mit Hilfe der Proteinbindungs-Methode erfolgt, wird Östron zunächst mit Natriumboranat zu Östradiol-17 $\beta$ reduziert; dadurch wird die Empfindlichkeit der Methode erhöht und gleichzeitig eine weitere Reinigung erzielt. Die Reagenzproteine für Testosteron und Progesteron werden aus Schwangerenplasma gewonnen, während das Reagenzprotein für Östriol aus der Cytosol-Fraktion des Schafuterus stammt.

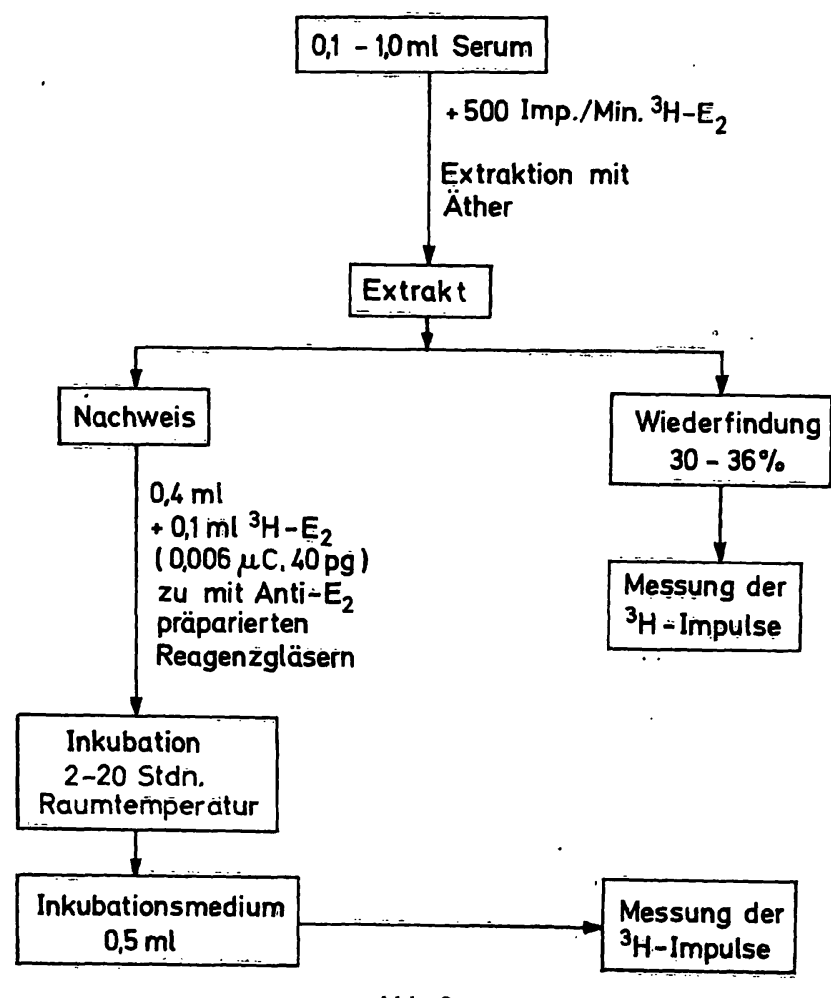

Abb. 3

Schematische Darstellung einer radioimmunochemischen Methode zur Bestimmung von Ostradiol-17 $\beta$ im Serum des Menschen nach ABRAHAM

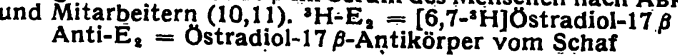


Differentialdiagnose von Herz- und Lebererkrankungen

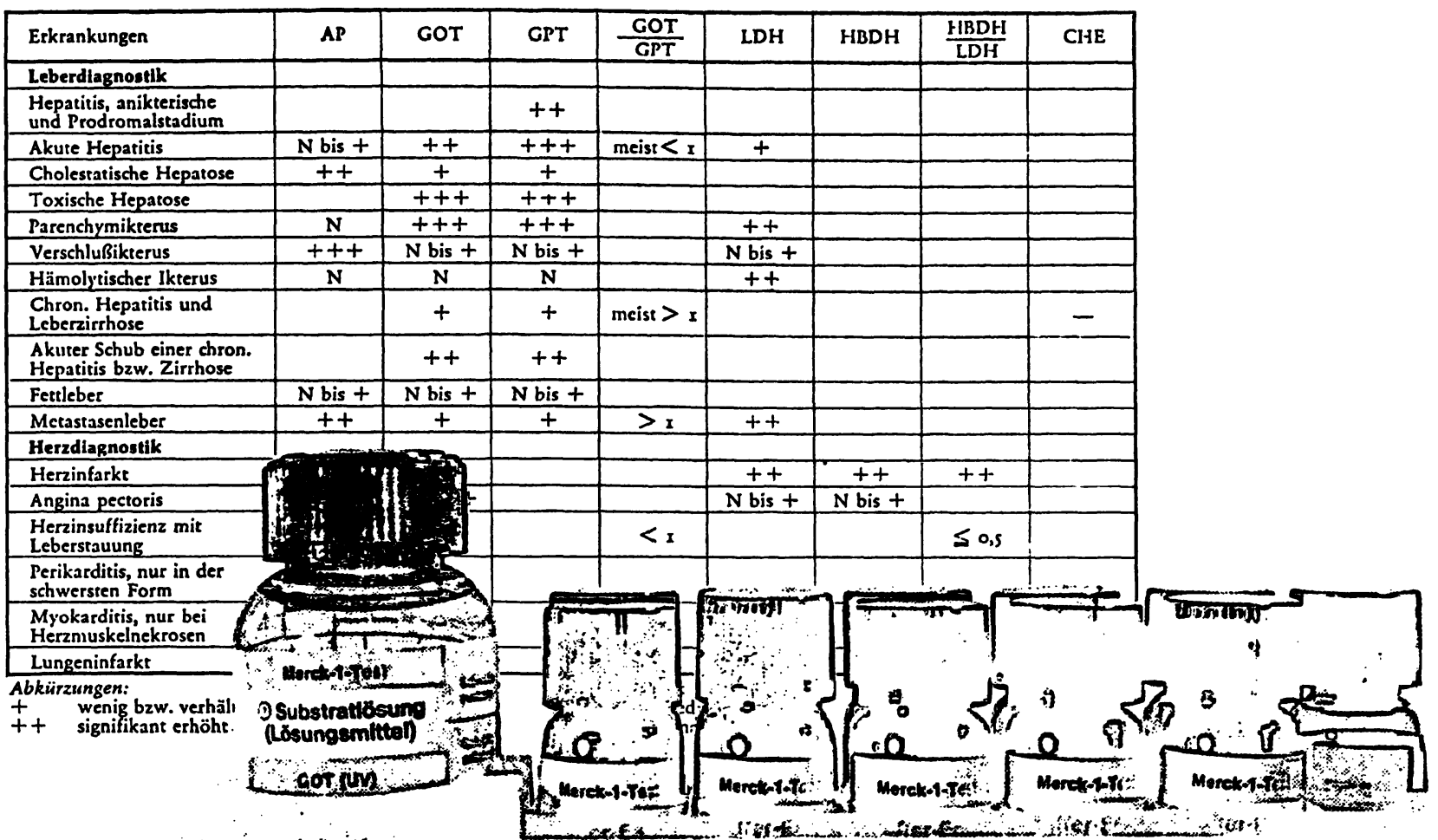
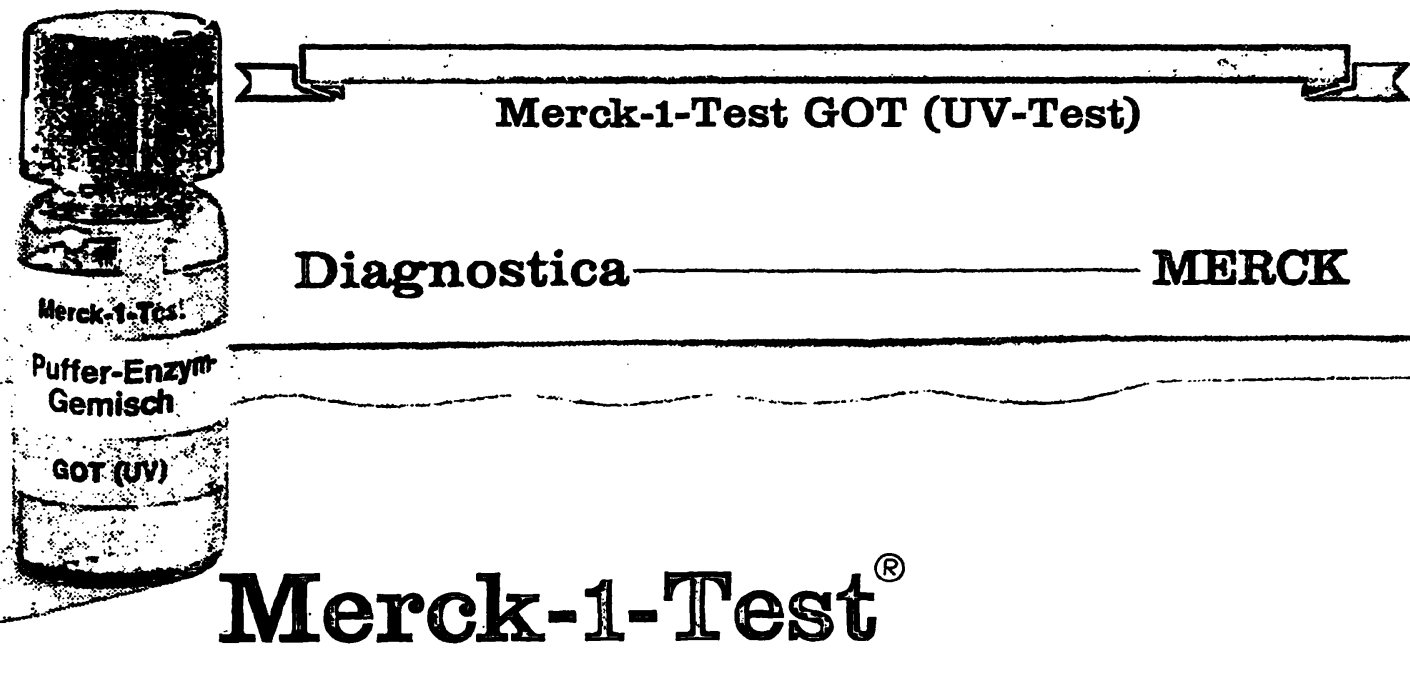

Diagnostica

MERCK

\section{Merck-1-Test}

Das moderne Konzept für Sicherheit und Zeitersparnis in Klinik- und Praxislabor.

Merck-1-Test ${ }^{\circ}$ Alkalische Phosphatase (kin. Test)

Merck-1-Test ${ }^{\circ}$ Cholinesterase (kin. Test)

Merck-1-Test ${ }^{\circ}$ GOT (UV)

Merck-1-Test ${ }^{\circ}$ GPT (UV)

Merck-1-Test ${ }^{\circ}$ HBDH (UV)

Merck-1-Test ${ }^{\circ}$ LDH (UV)

Verlangen Sie bitte unseren Spezial-Prospekt.

E. Merck, Darmstadt 


\section{Whatman-Austauscher gehören zu den absolữ zuverlässigen auch die Präzisions-Säulen * Chromatographie}

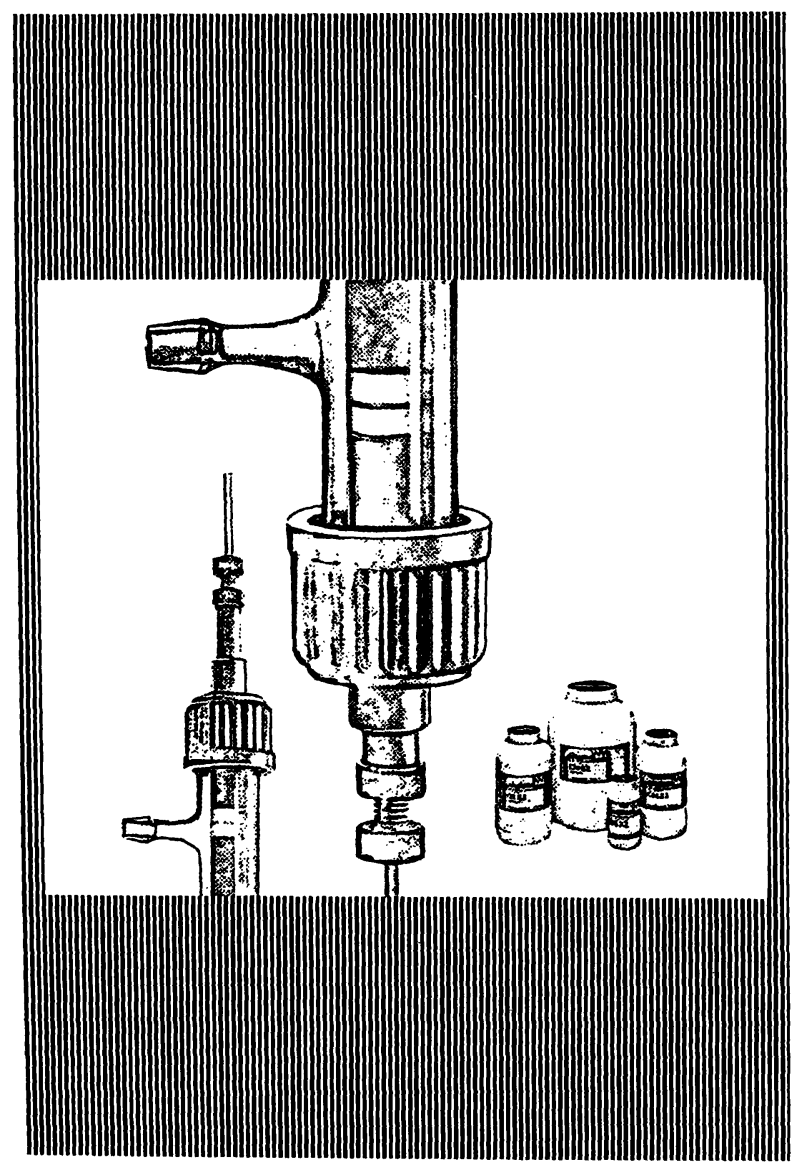

* Kennen Sie unser Labor Manual ?

Unsere interessante Druckschrift WHS-694 informiert Sie ausführlich.

WISSENSCHAFTLICHE APPARATE 1897 HORMUIH-VETTER

6908 Wiesloch/Bd., Postfach 1348, Tel. 06222/21 47 6900 Heidelberg 1, Postfach 750, Tel. 0622120045

\section{Ein neues}

Entwicklungssystem für DünnschichtChromatogramme Die CAMAG VARIO-KS-Kammer

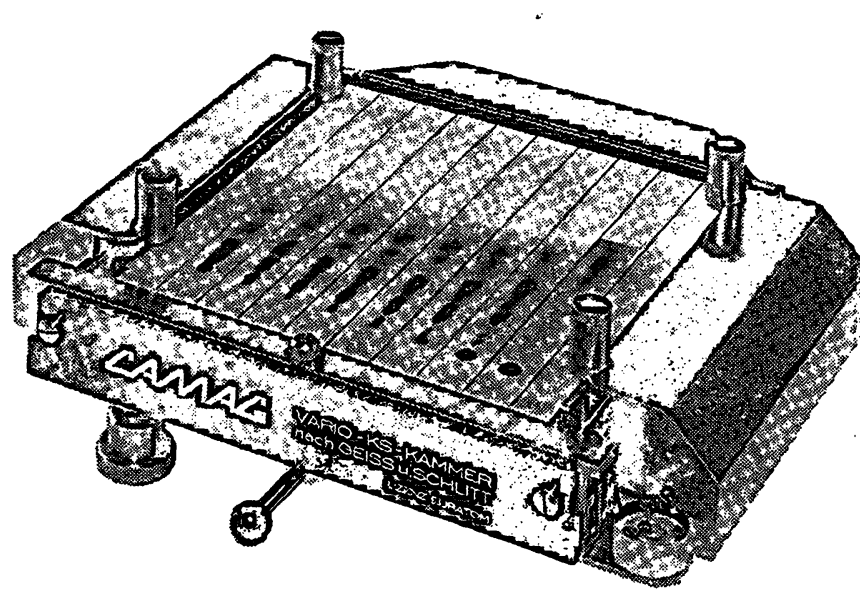

Entwicklung mit gezielter Schichtvorbeladung? optimale Trennergebnisse, vorausbestimmbares Trennverhalten.

Beeinflussung der Trenneigenschaften durch Längs- und Quergradienten.

Überlagerte Gradienten.

Substanzklassenanalyse.

Ausbildung von Feuchtegradienten zur Überbrückung grosser Polaritätsunterschiede im Trenngemisch.

Durchlaufchromatographie.

Die VARIO-KS-Kammer dient sowohl der Forschung als auch der Entwicklung leistungsfähiger Routineverfahren.

Ausführliche Beschreibung in unserem Prospekt 251-400.

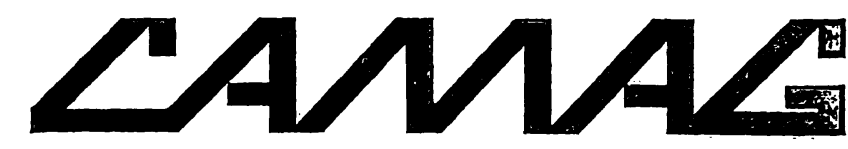

Homburgerstrasse 24 4132 Muttenz/Schweiz

Unser Zweigbetrieb in der Bundesrepublik:

1 Berlin 45, Baseler Strasse 65

Führend in Dünnschicht-Chromatographie Dünnschicht-Elektrophorese TL 29 Hochsparinungs-Elektrophorese 
Bei dem in Abbildung 3 dargestellten Verfahren handelt es sich um eine radioimmunochemische Proteinbindungs-Methode $(10,11)$. Da im Gegensatz zu den Gewebs- und Plasmaproteinen die Antikörper eine sehr hohe Spezifität für Östradiol-17 $\beta$ besitzen, kann bei dieser Methode auf komplizierte Reinigungsschritte verzichtet werden. Außerdem sind die radioimmunochemischen Methoden empfindlicher als die anderen Proteinbindungs-Methoden, so da $\beta$ mit geringeren Mengen an Ausgangsmaterial gearbeitet werden kann. $0,1-1,0 \mathrm{ml}$ Serum werden mit tritiiertem Östradiol-17 $\beta$ versetzt und mit Äther extrahiert. Ein Teil des Extraktes wird zur Ermittlung der Wiederfindung, ein weiterer Teil zum Nachweis der unbekannten Menge des endogenen Östrogens benutzt. $\mathrm{Zu}$ diesem Zweck wird der in Puffer aufgenommene und mit tritiiertem Östradiol-17 $\beta$ versetzte Extraktrückstand in Reagenzgläser überführt, die vorher mit Östradiol-17 $\beta$-Antikörpern präpariert wurden. Nach Inkubation wird ein Teil des Inkubationsmediums in Zählröhrchen überführt und die Radioaktivität gemessen.

Zusammenfassend ist zu bemerken, daß die kompetitiven Proteinbindungs-Methoden einen wesentlichen methodischen Fortschritt auf dem Gebiet der Steroidanalytik darstellen. Im Vergleich zu den klassischen chemischen Methoden ist die Empfindlichkeit der Proteinbindungs-Methoden ungleich höher. Mit geeigneten Verfahren können heute bis zu $10 \mathrm{pg}$ Steroid in einer Analysenprobe aus biologischem Material nachgewiesen werden. Die Proteinbindungs-Methoden sind jedoch keineswegs einfach $z u$ handhaben. Bedingt durch die hohe Empfindlichkeit sind sie sehr störanfällig und erfordern äußerst genaues und sauberes Arbeiten. Die Einarbeitung einer Proteinbindungs-Methode dauert im
Normalfall mehrere Monate. Trotz dieser Einschränkung werden diese Verfahren in vielen Fällen die älteren chemischen Methoden ablösen und damit die Bearbeitung neuer Fragestellungen möglich machen.

\section{Gaschromatographie}

Bereits kurz nach Einführung der Gaschromatographie in die biochemische Analytik wurde diese Methode zur qualitativen und quantitativen Bestimmung von Steroidhormonen herangezogen. Wie kaum ein anderes chromatographisches Hilfsmittel ist die gaschromatographische Säule in der Lage, in kurzer Zeit (Minuten) Verbindungen voneinander $z u$ trennen, die in ihrer chemischen Struktur sehr ähnlich sind. $\mathrm{Zu}$ solchen Verbindungen gehören in besonderer Weise die Metaboliten von Steroidhormonen, die sich zum Teil nur durch die verschiedenen Stellungen von Hydroxylgruppen oder Ketogruppen im Steroidmolekül unterscheiden. Das gilt sowohl für die Östrogene $\left(\mathrm{C}_{18^{-}}\right.$ Steroide) und Androgene ( $\mathrm{C}_{19}$-Steroide) als auch für die Gestagene und Corticoide $\left(\mathrm{C}_{21}\right.$-Steroide).

Die besondere Leistungsfähigkeit der Gaschromatographie sei am Beispiel der Ring B-substituierten Östrogene demonstriert (Abb. 4). Während der Inkubation von Östron mit der Mikrosomen-Fraktion der Rattenleber entstehen neben anderen Verbindungen $6 \alpha$-Hydroxyöstron, $6 \beta$-Hydroxyöstron und $7 \alpha$-Hydroxyöstron als Metaboliten. Um diese drei Verbindungen mit Hilfe der Papierchromatographie einwandfrei voneinander trennen zu können, ist die Anwendung dreier verschiedener Lösungsmittelsysteme (Formamid-imprägniertes Papier/Äthylacetat-Chloroform 4:1, Formamidimprägniertes Papier/Äthylacetat-Monochlorbenzol 3:1

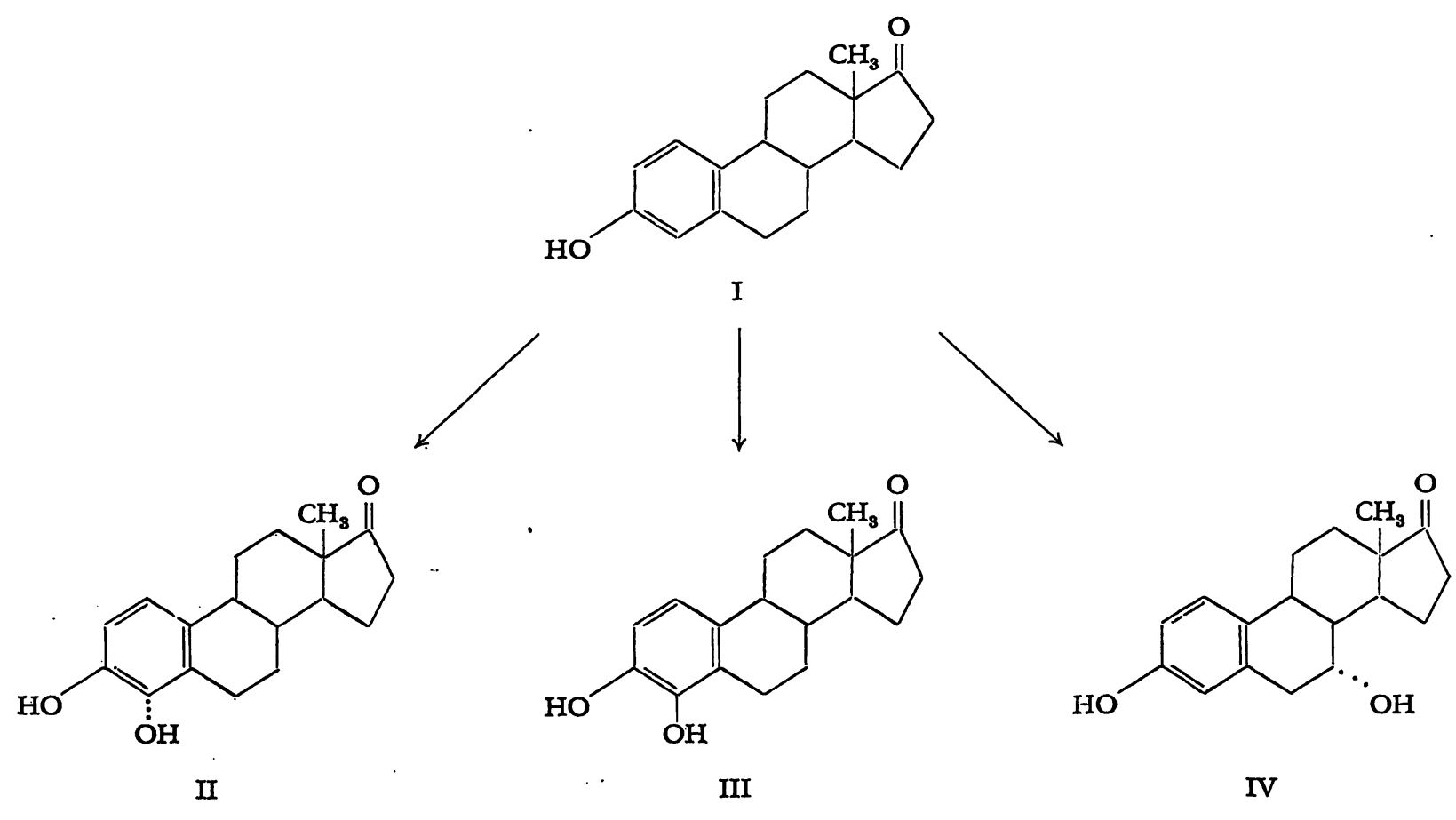

Abb. 4 Stoffwechsel von Ostron zu Ring B-hydroxylierten Metaboliten in der Mikrosomen-Fraktion der Rattenleber. Einzelheiten über die Inku-

$\begin{aligned} I & =\text { Ostron } \\ \text { II } & =6 \alpha-\text { Hydroxyöstron }\end{aligned}$

$\begin{aligned} \text { III } & =6 \beta \text {-Hydroxyöstron } \\ \text { IV } & =7 \alpha \text {-Hydroxyöstron }\end{aligned}$

Z. klin. Chem. u. klin. Biochem. / 8. Jahrg. 1970 / Heft 4 
sowie Methanol-Wasser-Benzol-Petroläther $7: 3: 4: 6$ ) notwendig. Dieses zeitraubende analytische Verfahren kann durch eine einmalige Gaschromatographie ersetzt werden. In den Abbildungen $5 \mathrm{a}$ und $5 \mathrm{~b}$ ist das Verhalten der drei Ring B-substituierten Östrogene an einer OV-1- und an einer OV-17-Säule dargestellt. Die auf Östriol bezogenen unterschiedlichen Retentionszeiten (RRT) der Trimethylsilyläther (TMS) von $6 \alpha-$ Hydroxyöstron, $6 \beta$-Hydroxyöstron und $7 \alpha$-Hydroxyöstron erlauben eine ausreichende Trennung der drei isomeren Östrogene an einer OV-1-Säule (Abb. 5a). Eine noch bessere Trennung mit relativen Retentionszeiten von 1,04 ( $6 \alpha$-Hydroxyöstron-TMS), 0,90 ( $6 \beta$ Hydroxyöstron-TMS) und 0,73 (7 $\alpha$-HydroxyöstronTMS) ergibt sich an einer OV-17-Säule (Abb. 5b).

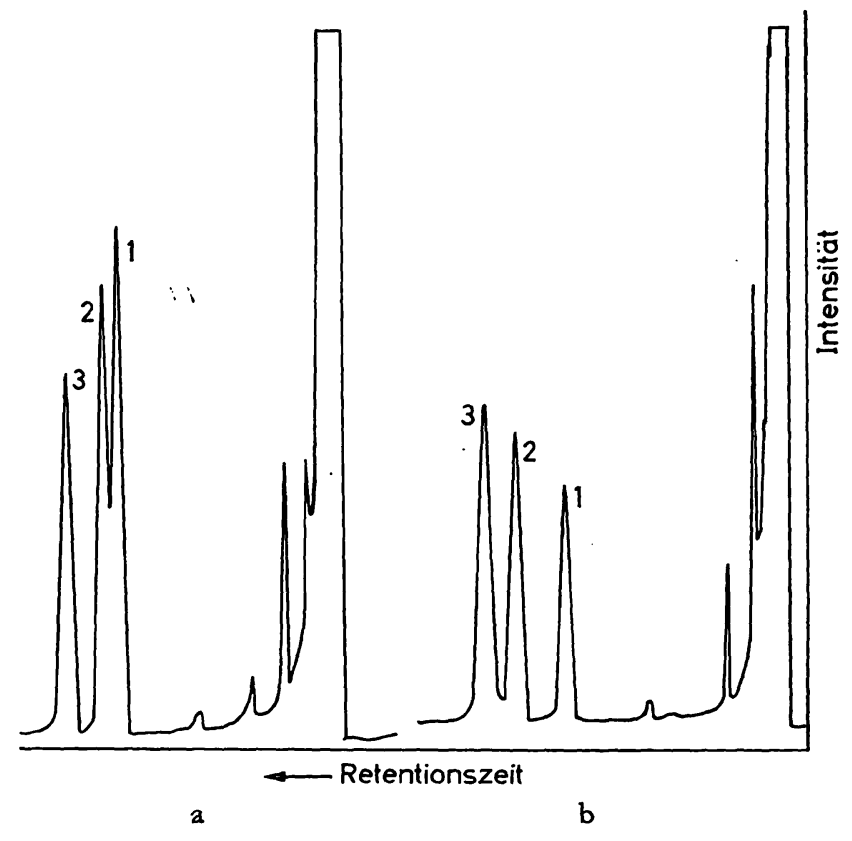

Abb. 5 a

Gaschromatogramm der Trimethylsilyläther von $6 \alpha-, 6 \beta-$ und $7 \alpha-$ Hydroxyöstron. Gaschromatographische Bedingungen: $3 \%$ OV-1 auf CinlaBtemperatur $210^{\circ}$; Detektortemperatur $230^{\circ}$; Stickstoffdurchfluß $35 \mathrm{ml} / \mathrm{Min}$. Gaschromatograph: Microtek MT $220 \mathrm{mit}$ Doppelflammen-Ionisationsdetektor

$1=7 \alpha$-Hydroxyöstron
$2=6 \beta$-Hydroxyöstron

$2=6 \beta$-Hydroxyöstron
$3=6 \alpha$-Hydroxyöstron

Abb. 5 b

Gaschromatogramm der Trimethylsilyäther von $6 \alpha-, 6 \beta-$ und $7 \alpha-$ Hydroxyöstron. Gaschromatographische Bedingungen: $3 \%$ OV-17 auf Chromosorb WHP $100 / 120 ; 180 \times 0,3 \mathrm{~cm}$; Säulentemperatur $220^{\circ}$; Einlaßtemperatur $225^{\circ}$; Detektortemperatur $230^{\circ}$; Stickstoffdurchfluß
$35 \mathrm{ml} /$ Min. Gaschromatograph: Mikrotek MT 220 mit DoppelflammenIonisationsdetektor

$1=7 \alpha$-Hydroxyöstron

$2=6 \beta$-Hydroxyöstron
$3=6 \alpha$-Hydroxyöstron

Der Nachweis der hier beschriebenen Verbindungen erfolgte mit einem Doppelflammen-Ionisationsdetektor. Der Substanzbedarf, der erforderlich ist, um ein gut auswertbares Gaschromatogramm zu erhalten, liegt im Bereich von 10-100 ng. Mit der Entwicklung des Elektronen-Einfang-Detektors (Electron capture detector) durch LOVELOCK und LIPSKY (13) eröffneten sich neue Möglichkeiten zum Nachweis noch geringerer Steroidmengen. Bevor jedoch die Steroide mit Hilfe des Elektronen-Einfang-Detektors bestimmt werden<smiles>[R]OC(=O)CCl</smiles><smiles>[R]OC(=O)C(F)(F)F</smiles><smiles>[R]OC(=O)C(F)(F)Cl</smiles><smiles>[R]OC(=O)C(F)(F)C(F)(F)C(F)(F)F</smiles><smiles>[R]O[Si](C)(C)CCl</smiles><smiles>[R]O[Si](C)(C)CBr</smiles>
Steroidester und Steroidäther, die zur gaschromatographischen $\mathrm{Be}$ $\mathrm{R}=$ Steroidrest
mit dem Elimmung

können, ist es notwendig, sie in geeignete Derivate zu überführen. In Abbildung 6 sind die wichtigsten Steroidester und Steroidäther zusammengestellt, die bei der Gaschromatographie mit Elektronen-Einfang-Detektoren Verwendung finden. Das am häufigsten benutzte Derivat ist das Heptafluorbutyrat; weitere Derivate für die Bestimmung der Steroide sind die Monochloracetate, die Monochlordifluoracetate, die Trifluoracetate, dieChlormethyl-dimethyl-silyläther und die Brommethyldimethyl-silyläther. Die häufige Verwendung der Heptafluorbutyrate erklärt sich aus der Tatsache, daß der Elektronen-Einfang-Detektor für diese Verbindungen die höchste Empfindlichkeit aufweist. So ist es möglich, die Heptafluorbutyrate authentischer Reinsubstanzen im Picogramm-Bereich, die aus biologischem Material gewonnenen Steroidheptafluorbutyrate im unteren Nanogramm-Bereich qualitativ und quantitativ zu bestimmen.

Auf einige Schwierigkeiten, die sich bei der Gaschromatographie von Steroiden mit Elektronen-Einfang-Detektoren ergeben, sei kurz eingegangen. (1) Für manche Steroidderivate arbeitet der Detektor nicht in allen Konzentrationsbereichen linear. (2) Bei Verwendung von Tritiumfolien als $\beta$-Strahler kann nur bis zu Temperaturen von $220^{\circ}$ gearbeitet werden; da die Säulentemperatur stets etwas unter der Detektortemperatur liegen sollte, können nur relativ kurze Säulen verwendet werden. Der bessere Trenneffekt langer Säulen kann deshalb nicht ausgenutzt werden. Die genannten Schwierigkeiten lassen sich durch den Einsatz von 
${ }^{63} \mathrm{Ni}-D e t e k t o r e n$ überwinden, da diese bei wesentlich höheren Temperaturen (bis $350^{\circ}$ ) arbeiten. (3) Ein weiteres Problem stellt die Derivatbildung von $\Delta^{4}-3$ Oxosteroiden dar, die mit Heptafluorbuttersäureanhydrid unter bestimmten Bedingungen neben Estern auch Enolester bilden können. Sowohl die Ester als insbesondere auch die Enolester sind so instabil, daB bei einer dünnschichtchromatographischen Vorreinigung die Gefahr einer Zersetzung besteht. (4) Bei der Bestimmung aus biologischem Material ist eine intensive Reinigung der nachzuweisenden Steroide durch Verteilung $z$ wischen verschiedenen Lösungsmitteln und durch andere chromatographische Verfahren (z. B. Säulen-, Dünnschicht- und/oder Papierchromatographie) notwendig. Durch diese Reinigungsschritte geraten häufig neue Verunreinigungen in die zu untersuchende Probe. Bei der sehr hohen Empfindlichkeit der Elektronen-Einfang-Detektoren können bereits geringste Mengen dieser Verunreinigungen Störungen hervorrufen.

Es liegt in der Natur der Gaschromatographie, daß eine über jeden Zweifel erhabene Identifizierung von Steroiden nicht möglich ist. Als einziges Mittel zur Identifizierung liefert die Gaschromatographie die Retentionszeit. Es wäre deshalb von Vorteil, weitere physikalische und chemische Daten über die gaschromatographisch gereinigten und getrennten Steroidhormone zu erhalten. Als besonders geeignete Möglichkeit zur Identifizierung hat sich in jüngerer Zeit die Kombination des Gaschromatographen mit dem Massenspektrometer erwiesen. Es gibt zwei Methoden, um die Gaschromatographie in Kombination mit der Massenspektrometrie bei der Bestimmung von Steroid- hormonen einzusetzen: (1) Zur Identifizierung von Substanzen und zur Spezifitätsprüfung analytischer Verfahren; (2) Zum spezifischen Substanznachweis. Zunächst soll auf die erste der beiden Möglichkeiten näher eingegangen werden. $\mathrm{Zu}$ diesem $\mathrm{Zweck}$ ist in Abbildung 7 das kombinierte Gaschromatograph-Massenspektrometer schematisch wiedergegeben. An der gaschromatographischen Säule wird das Steroidgemisch aufgetrennt; im Molekülseparator wird das Trägergas (Helium) entfernt. Die zu bestimmenden Steroide werden in der Ionenquelle ionisiert, fragmentiert und beschleunigt. Das Magnetfeld trennt die Ionen nach $\mathrm{m} / \mathrm{e}$-Werten ( $\mathrm{m} / \mathrm{e}=$ Masse/Ladung) und lenkt sie auf den Sekundärelektronen-Vervielfacher ab. Die im Sekundärelektronen-Vervielfacher erzeugten Signale werden verstärkt und mit einem UV-Lichtpunktschreiber aufgezeichnet. Noch vor der Trennung durch den Magneten wird ein Teil des Totalionenstroms verstärkt und auf einen Linienschreiber übertragen. Dieser Linienschreiber dient zur Aufzeichnung des Gaschromatogrammes. Sobald der interessierende gaschromatographische Gipfel erscheint, wird eine Abtastung mit dem Magnetfeld ausgelöst; auf diese Weise wird für einen Teil des gaschromatographischen Gipfels das Massenspektrum aufgenommen und die Identität des Steroids nachgewiesen.

Ein Beispiel für diese Möglichkeit zur Identifizierung von Steroiden mit Hilfe der kombinierten Gaschromatographie und Massenspektrometrie sei der Arbeit von JÄNNE und VIHKo (14) entnommen. Abbildung 8 gibt ein Gaschromatogramm der Monosulfat-Fraktion aus dem Urin der Frau wieder. Die Monosulfat-Fraktion war vor der Gaschromatographie hydrolysiert und ge-
Abb. 7

Schematische Darstellung eines komb. Gaschromatograph-Massenspektrometers

GC-Säule = Gaschromatographische Säule MID = Multiple Ion Detector SEV $=$ Sekundärelektronen-Vervielfacher

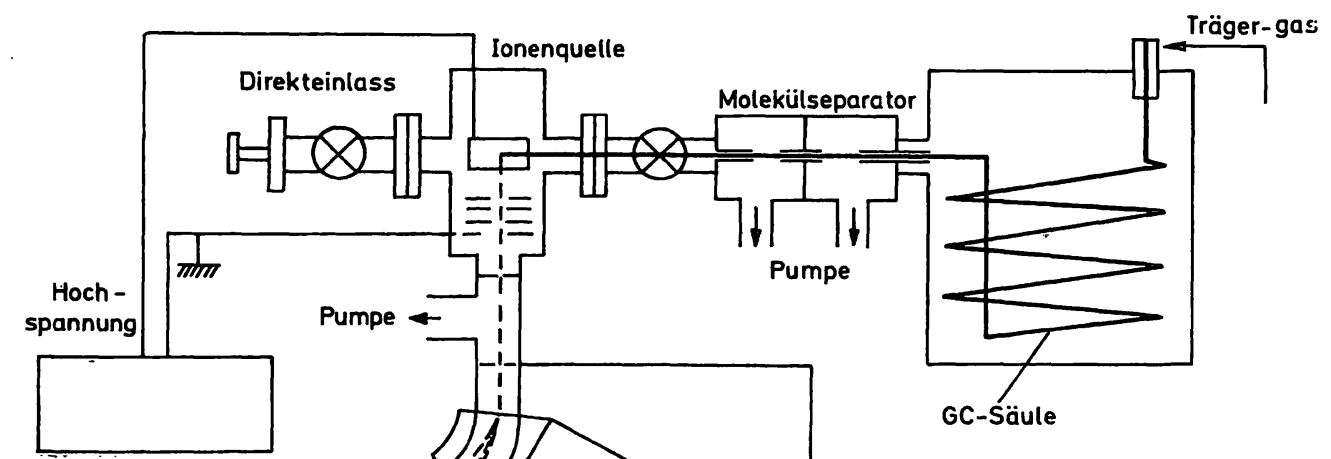

MID

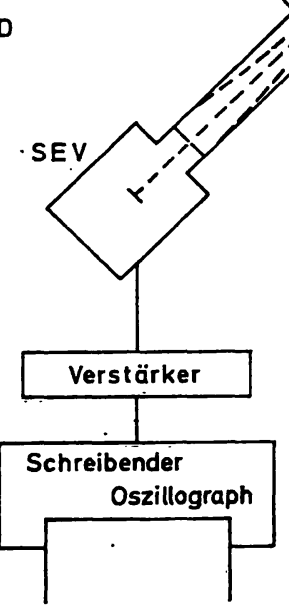

Magnet

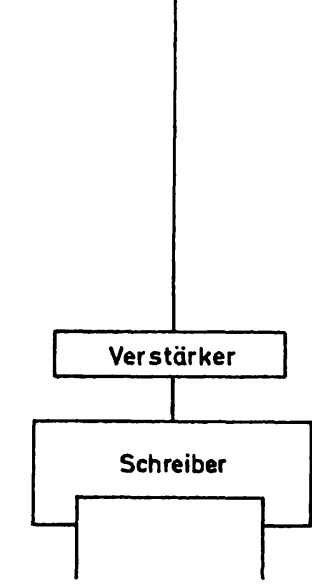

Z. klin. Chem. u. klin. Biochem. / 8. Jahrg. 1970 / Heft 4 


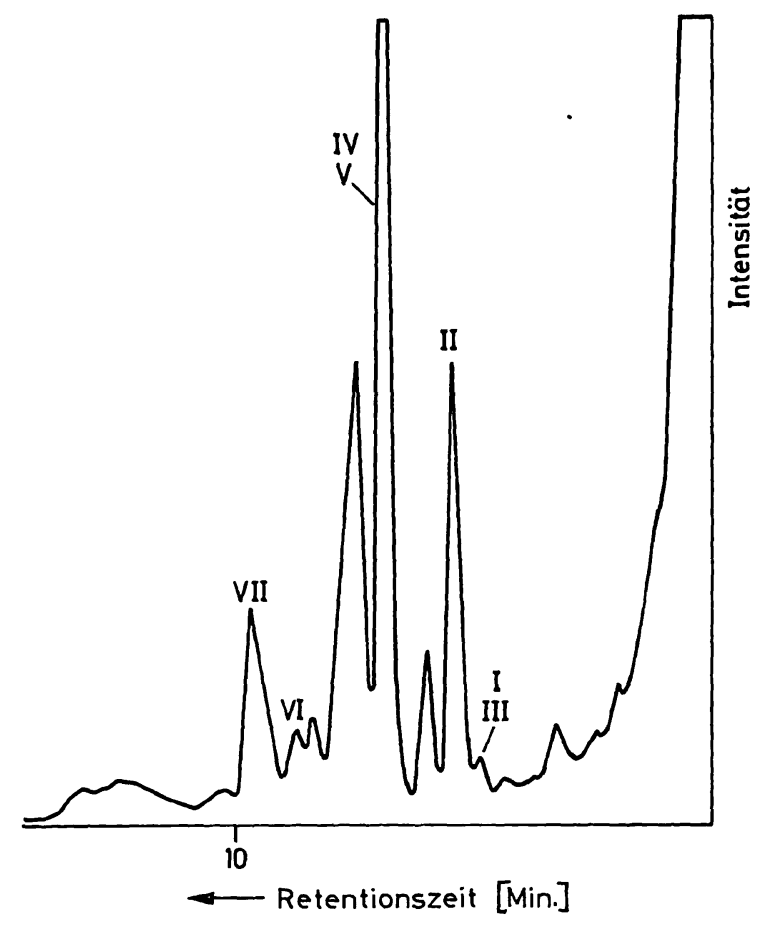

Abb. 8

Gaschromatogramm der Monosulfat-Fraktion aus dem Urin der Frau nach vorangegangener Hydrolyse und Reinigung. Es wurden die Methoxim-trimethylsilyl-derivate untersucht. Gaschromatographische Bedingungen: $3 \%_{0}^{\circ}$ QF-1; Säulentemperatur 215. Nach JÄNNE und VIHKO (14)

reinigt worden. Es zeigte sich eine Vielzahl gaschromatographischer Gipfel, deren Identifizierung auf Grund der Retentionszeiten alleine nicht durchführbar war. Von allen Gipfeln wurden Massenspektren aufgenommen, die - nach Vergleich mit den authentischen Substanzen - eine eindeutige Identifizierung erlaubten. Dies trifft z. B. auch für den Gipfel II des Gaschromatogramms zu. Das Massenspektrum des Methoxim-trimethylsilyl-derivates ist identisch mit demjenigen von authentischem 16 $\alpha$-Hydroxyandrosteron (Abb. 9). Wie dieses Beispiel zeigt, ist die Massenspektrometrie ein ausgezeichnetes Verfahren zur Identifizierung gaschromatographisch aufgetrennter Steroide. Der Substanzbedarf dieser Methode liegt, wie eigene Erfahrungen gezeigt haben, zwischen 50 und $100 \mathrm{ng}$ Steroid.

Wenn, wie soeben dargelegt, die GaschromatographieMassenspektrometrie einerseits zur Spezifitätsprüfung geeignet ist, so sollte es andererseits möglich sein, die Methode auch für einen spezifischen Substanznachweis zu verwenden. Daraus ergibt sich die zweite Möglichkeit des Einsatzes dieser Gerätekombination. Abbildung 7 zeigt, daß das Massenspektrometer auch als hochspezifischer Detektor benutzt werden kann. Dabei wird folgende Technik, die man nach einem Vorschlag von Hammar, Holmstedt und Ryhage (15) auch als Fragmentographie bezeichnen kann, angewendet. Man stellt mit dem Magnetfeld einen bestimmten $\mathrm{m} / \mathrm{e}$-Wert fest ein, so daß entweder das Molekülion oder ein Fragmention des zu messenden Steroidhormons auf dem Sekundärelektronen-Vervielfacher abgebildet wird. Diese Einstellung erfolgt mit Hilfe authentischer Reinsubstanz, die durch den Direkteinlaß in die Ionenquelle des Massenspektrometers gebracht wird. Durch Veränderung der Hochspannung mit dem Multiple Ion Detector (MiD) ist es möglich, das Massenspektrometer auf mehrere Massen einzustellen. Während der Aufnahme eines Chromatogramms schaltet der Multiple Ion Detector fortlaufend zwischen den vorgewählten Masseneinstellungen um. Dadurch werden die verschiedenen Massen des fragmentierten Steroidmoleküls auf dem Lichtpunktschreiber aufgezeichnet. Eine Veränderung, d. h. eine Verminderung der Hochspannung, ist nur bis zu etwa 20\% möglich, da sonst die Intensität des Signales der höheren Masse zu gering wird. Aus diesem Grunde können bei der hier beschriebenen Fragmentographie nur Massen innerhalb eines Bereiches von $20 \%$ aufgezeichnet werden.

Die Möglichkeiten der sog. Fragmentographie bei der spezifischen Bestimmung von Steroidhormonen sind im folgenden an den Beispielen von Aldosteron und von Östriol dargestellt. Das in Abbildung 10 wiedergegebene Massenspektrum von authentischem Aldosteron-trimethylsilyläther zeigt einen prominenten Gipfel bei einem $\mathrm{m} / \mathrm{e}$-Wert von 401; daneben findet sich ein weiterer Gipfel bei einem m/e-Wert von 414. Auf diese beiden $\mathrm{m} / \mathrm{e}$-Werte wird das Massenspektrometer mit Hilfe des Multiple Ion Detektors eingestellt. Zur Bestimmung von Aldosteron mit Hilfe der Fragmentographie wurden $25 \mathrm{~m} l$ Urin hydrolysiert, das freigesetzte Steroid extrahiert, der Extrakt durch Lösungsmittelverteilung gereinigt und der steroidhaltige Rück-

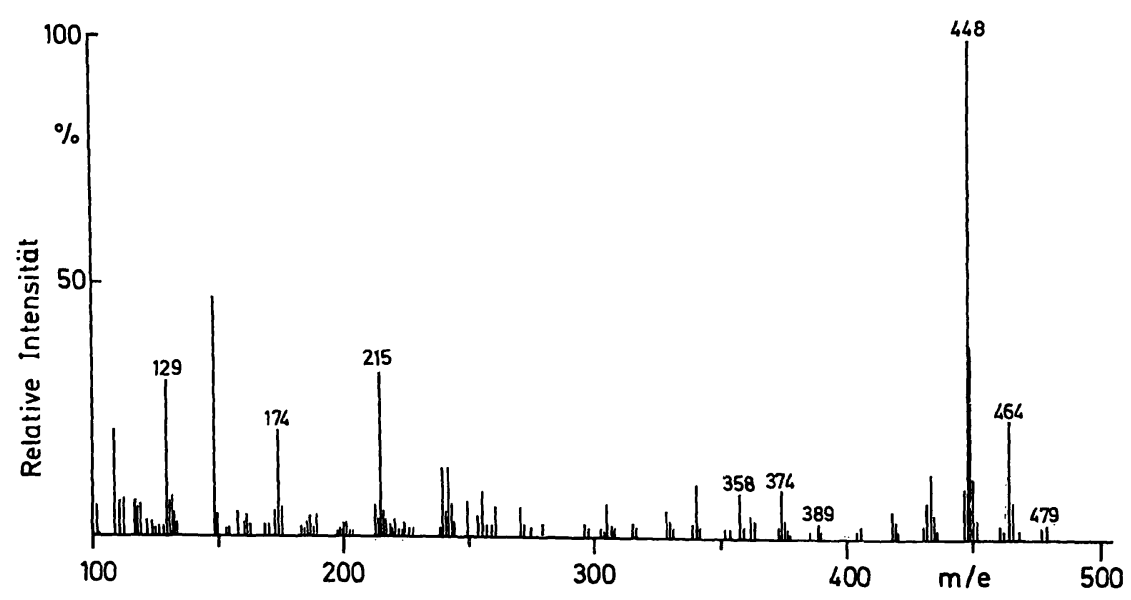

Abb. 9

Massenspektrum des Gipfels II aus dem Gaschromatogramm (vgl. Abb. 8) der MonosulfatFraktion aus dem Urin der Frau nach vorangegangener Hydrolyse und Reinigung.
Nach JÄNNE und VIHKO (14)

Z. klin. Chem. u. klin. Biochem: / 8. Jahrg. 1970 / Heft 4 


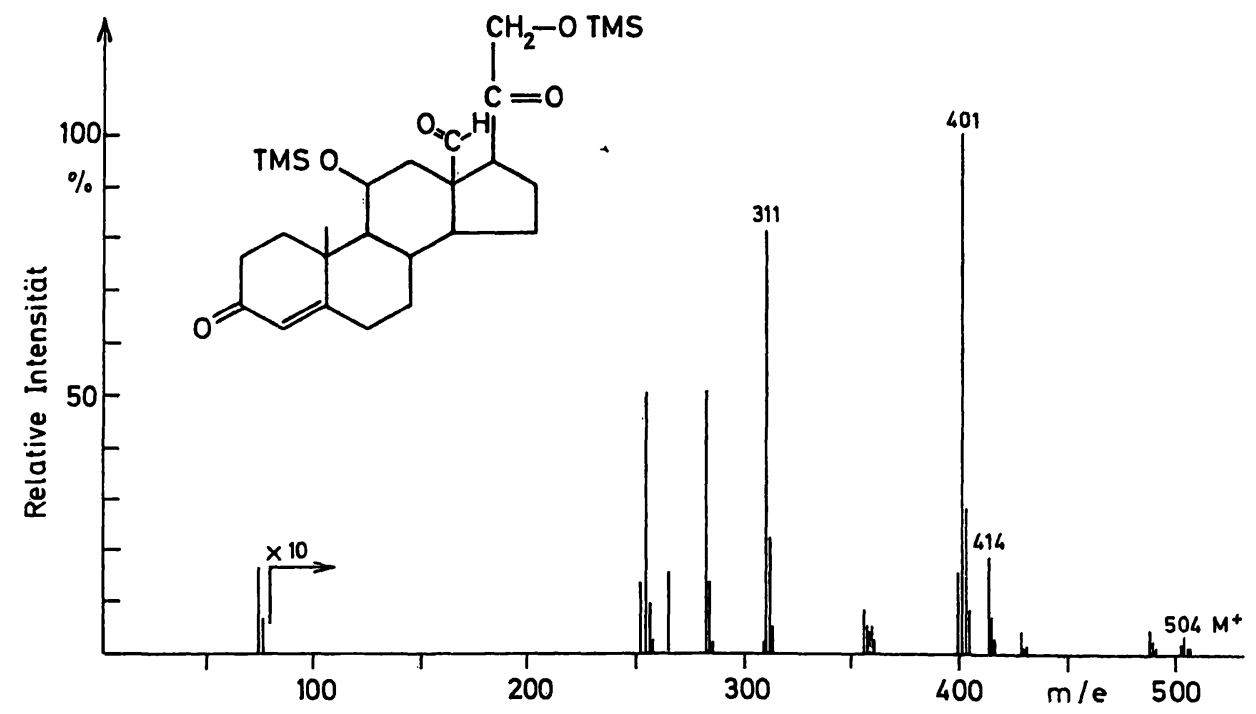

Abb. 10

Massenspektrum des Aldosteron-trimethylsilyläthers. Die Aufnahme des Massenspektrums erfolgte mit dem Gaschromatograph-Massenspektrometer LKB 9000. Gaschromatographische Bedingungen: $3 \%$ OV-3 auf Chromosorb WHP 100/120 $180 \times 0,25 \mathrm{~cm}$; Säulentemperatur $240^{\circ}$ Separatortemperatur $230^{\circ}$; Massenspek: trometrische Bedingungen: Ionenquellentemperatur $250^{\circ}$; I onisierungsenergie $35 \mathrm{eV}$. onisierungsstrom $60 \mu \mathrm{A}$. Nach SIEKMANN, HOPPEN und BREUER (16). TMS = Trimethylsilyl

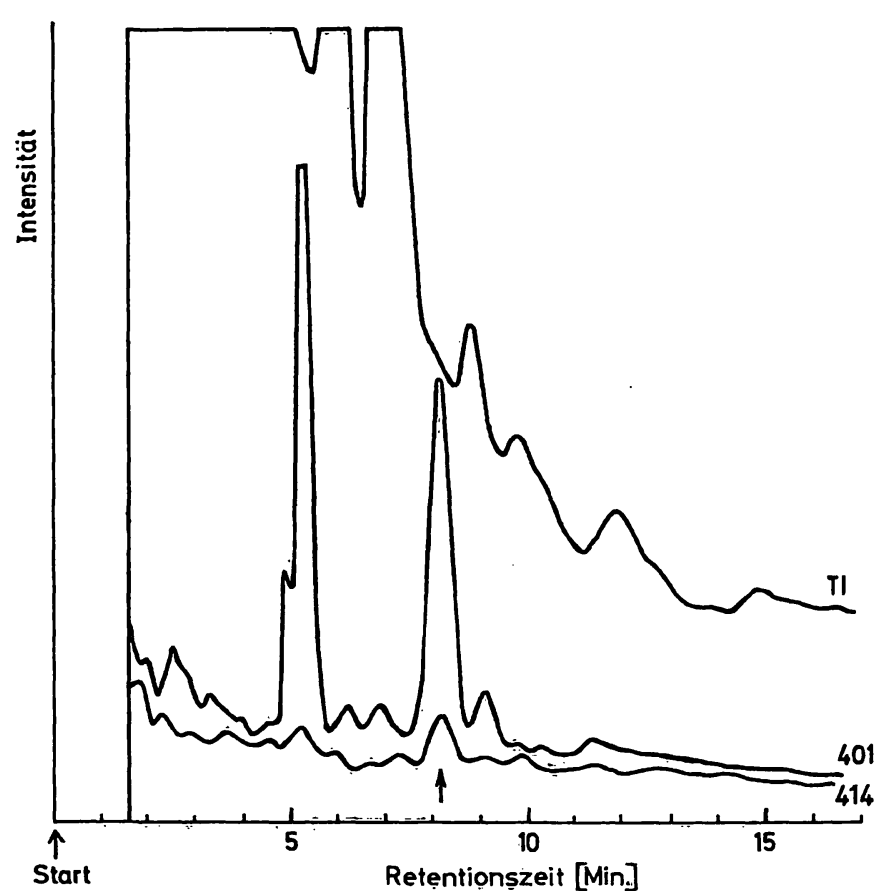

Abb. 11

Bestimmung von Aldosteron im Urin des Menschen mit Hilfe der Fragmentographie. Gaschromatogramme des Totalionenstroms (TI) sowie der m/e-Werte 401 und 414. Die Aufnahmen erfolgten mit dem Gaschromatograph-Massenspektrometer LKB 9000. Gaschromatographische Bedingungen: $3 \%$ OV -3 auf Chromosorb WHP 100/120 $180 \times 0,25 \mathrm{~cm}$; Säulentemperatur $240^{\circ}$; Separatortemperatur $230^{\circ}$. Massenspektrometrische Bedingungen: Ionenquellentemperatur $270^{\circ}$. Ionisierungsenergie $20 \mathrm{eV}$; Ionisierungsstrom $60 \mu \mathrm{A}$; Auflösungsvermögen R10\% T500. Nạch SIEKMANN, HOPPEN und BREUER (16) stand silyliert. Das Fragmentogramm eines Zehntels der aus dem Urin gewonnenen Aldosteron-Fraktion ist in Abbildung 11 wiedergegeben. Während - bedingt durch den Überschuß an störenden Substanzen - der Totalionenstrom ein uncharakteristisches Verhalten zeigt, treten bei den für Aldosteron charakteristischen $\mathrm{m} / \mathrm{e}-$ Werten von 401 und 414 zwei gut auswertbare Gipfel auf. Das gleichzeitige Auftreten beider Gipfel in dem gemessenen Verhältnis beweist eindeutig die Anwesenheit von Aldosteron im Urinextrakt. Die Aldosteronmenge, die durch die beiden Gipfel angezeigt wird, beträgt etwa $40 \mathrm{ng}$.

Das Massenspektrum von authentischem Östriol-trimethylsilyläther ist in Abbildung 12 wiedergegeben und läßt das Molekülion mit der Masse 504, auf das fokussiert werden soll, deutlich erkennen. Zur Bestimmung von Östriol im Schwangerenplasma wurde folgendermaßen verfahren. $2,5 \mathrm{ml}$ Plasma wurden zur Spaltung der Östriol-Konjugate hydrolysiert; anschließend wurden $400 \mathrm{ng}$ 6,7-Dideuteroöstriol als interner Standard zugesetzt. Das hydrolysierte Plasma wurde extrahiert, der Extrakt gereinigt und der Extraktrückstand silyliert. Ein Zehntel der Östriol-trimethylsilyläther-Fraktion wurde in das Kombinationsinstrument gegeben, das einmal auf die Masse des Molekülions (504) von natürlichem Östriol, zum anderen auf die Masse des Molekülions von 6,7-Dideuteroöstriol (506) ein-

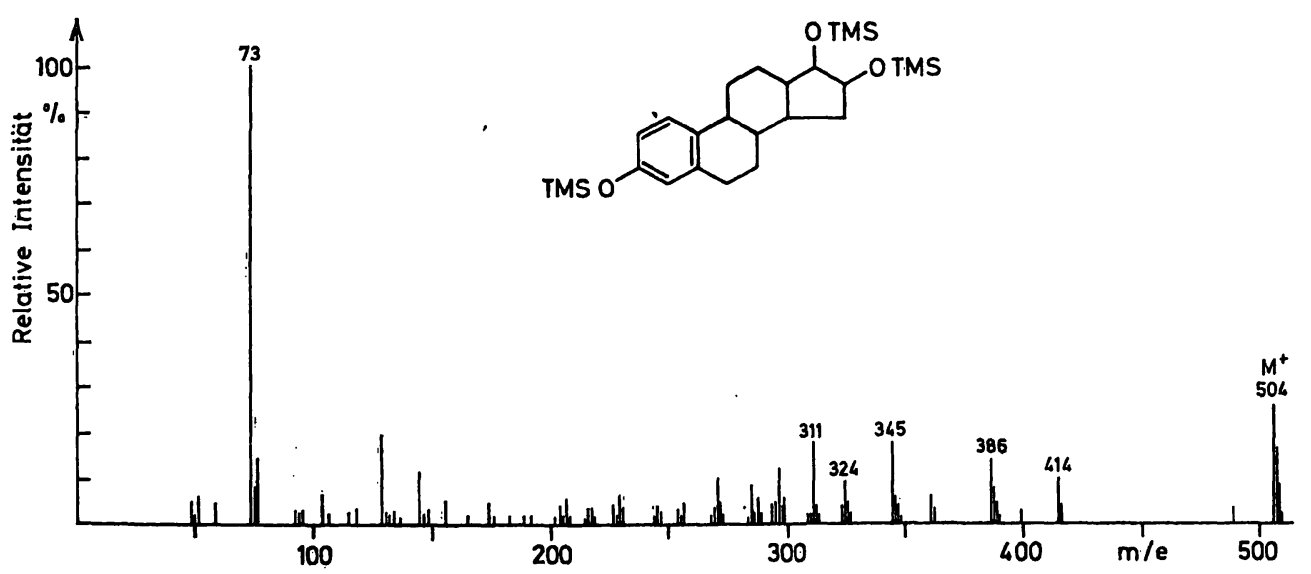

Abb. 12

Massenspektrum des Ostriol-trimethylsilyläthers. Die Aufnahme des Massenspektrums erfolgte mit dem Gaschromatograph-Massenspektrometer 9000 . Gaschromatographische Bedingungen: $3 \%$ OV-1 auf Chromosorb WHP 100/120; $180 \times 0,25 \mathrm{~cm}$; Säulentemperatur $235^{\circ}$; Separatortemperatur Massenspektrometrische Bedingungen vgl. Legende zu Abb. 10 


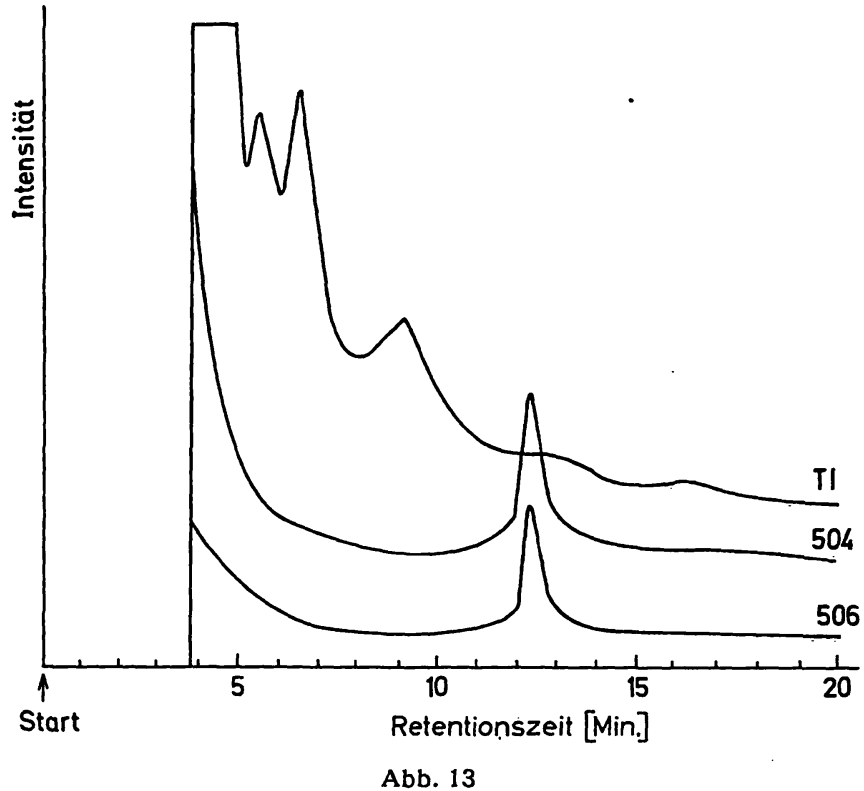

Bestimmung von Ostriol im Schwangerenplasma mit Hilfe der Fragmentographie. Gaschromatogramme des Totalionenstroms (TI) sowie Östriol und 6,7-Dideuteroöstriol). Die Aufnahmen erfolgten mit dem Gaschromatograph-Massenspektrometer LKB 9000. Gaschromatographische Bedingungen vgl. Legende zu Abb. 12. Massenspektroenergie $23 \mathrm{eV}$; Ionisierungsstrom $60 \mu \mathrm{A}$; Auflösungsvermögen $\mathrm{R}_{10} \% \mathrm{~T} 600$

gestellt worden war. Wie aus Abbildung 13 hervorgeht, treten bei der für Östriol erwarteten Retentionszeit die beiden charakteristischen Gipfel für Östriol bei einem $\mathrm{m} / \mathrm{e}$-Wert von 504 und für 6,7-Dideuteroöstriol bei einem $\mathrm{m} / \mathrm{e}$-Wert von 506 auf; der Totalionenstrom zeigt wiederum wegen der vorhandenen Verunreinigungen einen uncharakteristischen Verlauf. Der besondere Vorteil des Zusatzes von 6,7-Dideuteroöstriol zu $\operatorname{der} \mathrm{zu}$ analysierenden Probie liegt darin begründet, daß vom Beginn der Analyse an ein interner Standard mitgeführt wird, durch den alle methodischen Verluste bei der Probenaufarbeitung und Gaschromatographie automatisch korrigiert werden. Für die Berechnung des ursprünglich im Extrakt vorhandenen Östriol ist ausschließlich das im Massenspektrometer bestimmte Mengenverhältnis von natürlichem Östriol und 6,7Dideuteroöstriol maßgebend. Die Östriolmenge, die durch die beiden Gipfel angezeigt wird, beträgt etwa $28 \mathrm{ng}$.

Die hier an einigen Beispielen dargelegten Entwicklungen auf dem Gebiet der Steroidanalytik lassen keinen Zweifel daran, daB während der letzten Jahre erhebliche Fortschritte erzielt wurden. Durch Einsatz der Proteinbindungs-Methoden, der Gas'chromatographie und der Massenspektrometrie wird es möglich sein, zahlreiche, bisher ungelöste Probleme der experimentellen und klinischen Endokrinologie zu bearbeiten. Darüber hinaus hat und wird die biochemische Analytik durch diese Entwicklungen wesentliche Bereicherungen auf methodischem Gebiet erfahren.

\section{Literatur}

1. Ekins, R. und B. Newwan, In: Steroid Assay by Competitive Protein Binding, 2nd Karolinska Symposium on Research Methods in Reproductive Endocrinology (1970), in press. - 2. MurpHy, B. E. P., In: Steroid Assay by Competitive Protein Binding, 2nd Karolinska Symposium on Research Methods in Reproductive Endocrinology (1970), in press. - 3. Korenman, S. G., L. E. Perrin und T. P. McCallum, J. Clin. Endocr., Springfield 29 879 (1969). - 4. Robinson, R. G. und D. D. Fanestil, In: Steroid Assay by Competitive Protein Binding, 2nd Karolinska Symposium on Research Methods in Reproductive Endocrinology (1970), in press. - 5. Beiser, S. M. und B. F. ERLANGer, Nature, London 214, 1044 (1967). - 6. Murphy, B. E. P., Recent Progr. Hormone Res. 25, 563 (1969). - 7. Korenman, S. G., Steroids 13, 163 (1969). - 8. Westphal, U., Arch. Biochem. Biophysics 118, 556 (1967). - 9. Young, P., C. A. Woolever und R. Borth, in Vor- bereitung. Mitgeteilt von R. BoRTH auf dem 2nd Karolinska Symposium on Research Methods in Reproductive Endocrinology, Geneva, 23.-25. 3. 1970. - 10. AbrahaM, G. E., J. Clin. Endocr., Springfield 29, 866 (1969). - 11. AbrahaM, G. E., W. D. OdeLL, R. Edwards und J. M. Purdy, In: Steroid Assay by Competitive Protein Binding, 2nd Karolinska Symposium on Research Methods in Reproductive Endocrinology (1970), in press. - 12. LEHMANN, W. D. und H. Breuer, Hoppe-Seylers Zschr. physiol. Chem. 350, 191 (1969). - 13. LoveloCK, J. E. und S. R. Lripskx, J. Amer. chem. Soc. 82, 431 (1960). - 14. JÄNNE, O. und R. VIhKo, Steroids 14, 235 (1969). - 15. Hammar, C.-G., B. HolmstedT und R. Ryhage, Analytic. Biochem. 25, 532 (1968). - 16. SreKMANN, L., H.-O. Hoppen und H. Breuer, Zschr. analyt. Chemie, im Druck.

Prof. Dr. H. Breuer 53 Bonn,

Venusberg 